\title{
T-type channels buddy up
}

\author{
Ray W. Turner • Gerald W. Zamponi
}

Received: 17 December 2013 / Accepted: 23 December 2013 / Published online: 11 January 2014

(C) The Author(s) 2014. This article is published with open access at Springerlink.com

\begin{abstract}
The electrical output of neurons relies critically on voltage- and calcium-gated ion channels. The traditional view of ion channels is that they operate independently of each other in the plasma membrane in a manner that could be predicted according to biophysical characteristics of the isolated current. However, there is increasing evidence that channels interact with each other not just functionally but also physically. This is exemplified in the case of Cav3 T-type calcium channels, where new work indicates the ability to form signaling complexes with different types of calciumgated and even voltage-gated potassium channels. The formation of a Cav3-K complex provides the calcium source required to activate $\mathrm{KCa} 1.1$ or $\mathrm{KCa} 3.1$ channels and, furthermore, to bestow a calcium-dependent regulation of Kv4 channels via associated KChIP proteins. Here, we review these interactions and discuss their significance in the context of neuronal firing properties.
\end{abstract}

Keywords Cav3 $\cdot \mathrm{T}$-type $\cdot \mathrm{KCa} 3.1 \cdot \mathrm{KCa} 1.1 \cdot \mathrm{BK} \cdot \mathrm{Kv} 4 \cdot$ A-type

\section{Introduction}

Control over the frequency and pattern of neuronal spike output defines neural coding of information in the brain. Central to this process are ion channels that conduct potassium to control excitability by hyperpolarizing the membrane

This article is published as part of the Special Issue on T-type (Cav3) calcium channels in health and disease.

R. W. Turner $(\triangle)$

Department of Cell Biology and Anatomy, Hotchkiss Brain Institute,

University of Calgary, HRIC Bldg, Room 1AA14, 3330 Hospital Dr.

N.W., Calgary T2N 4N1, Alberta, Canada

e-mail: rwturner@ucalgary.ca

URL: http://www.acs.ucalgary.ca/ rwturner

R. W. Turner · G. W. Zamponi

Department of Physiology and Pharmacology, Hotchkiss Brain Institute, University of Calgary, Calgary T2N 4N1, Alberta, Canada potential. We know of numerous isoforms of voltage-gated potassium channels that contribute to controlling excitability $[23,47]$. But few of these have as key a role in regulating the frequency and pattern of spike discharge as calcium-gated potassium channels [135]. A great deal of work has focused on the ability for high-voltage-activated (HVA) calcium channels to activate either small conductance (SK, KCa2.x) [2, 76, $125]$ or big conductance $(\mathrm{BK}, \mathrm{KCa} 1.1)$ potassium channels to control cell excitability [10-12, 45, 139]. Calcium-dependent control of potassium channels has also been recognized to reflect interactions at the level of either a microdomain or nanodomain, a designation that signifies an interchannel distance of $<50$ or 50-200 nm, respectively [36]. This is important because it reflects an entirely different degree of control that calcium influx can exert on potassium channel activation that may be necessary to effect different cellular functions. Indeed, interactions at the nanodomain level can allow the voltage dependence of specific HVA calcium channel isoforms to be conferred onto KCa1.1 channels [11], providing greater control over the onset voltage and time of hyperpolarizing currents.

Until recently there were only a few reports of Cav3 (Ttype) calcium channels being functionally coupled to activation of either KCa2.x $[26,138]$ or KCa1.1 $[44,111]$ channels. This coupling was defined entirely on the basis of physiological interactions with little protein biochemical work to assess the nature of the link or its control of potassium channel function at the level of a microdomain or nanodomain. Recent work reveals that Cav3 calcium channels can form an association at the molecular level with calcium-gated potassium channels and even a voltage-gated potassium channel. Thus, Cav3 channels have been shown through protein biochemical and biophysical analyses to associate closely with $\mathrm{KCa} 1.1$ channels [101] as well as intermediate conductance calcium-activated potassium channels (KCa3.1, SK4, $\mathrm{KCa} 3.1)$ [34]. Moreover, an association at the molecular level was detected between Cav3 channels and the Kv4 family of voltage-gated potassium channels that generate transient Atype currents $[4,5]$. In each case linking potassium channel activation to calcium influx through Cav3 channels allows 
outward current to be triggered from membrane voltages well below resting membrane potential and even over the course of a full-blown spike response. Interestingly, activation of these potassium channels by Cav3 calcium influx relies on three distinct calcium sensing mechanisms. The ability for these complexes to function at either a microdomain or nanodomain level proves to depend on the sensitivity of the calcium sensor in relation to the relatively weak conductance of Cav3 channels compared to HVA calcium channels.

Several recent reviews have been published on the properties of T-type calcium channels on topics that will not be covered here $[16,20,27,51,64,65,100,120,137]$. This review summarizes the current state of knowledge of how Cav3 channel associate with three distinct forms of potassium channel to form ion channel complexes that acquire functional roles that reflect the combination of biophysical properties of each partner in the complex. To fully understand the interplay between calcium and potassium channels, we briefly summarize key features of the responsible subunits and proteins involved.

\section{Cav3 calcium channels}

Voltage-gated calcium channels permit the entry of calcium ions into the cytosol in response to membrane depolarizations. Voltage-gated calcium channels can be divided into two major families: HVA calcium channels that open in response to large membrane depolarizations and low-voltage-activated (LVA) channels that open in response to smaller membrane depolarizations [122]. The HVA channels include L-, P-, Q-, N-, and R-types which can be distinguished based on their biophysical and pharmacological properties. HVA channels share a common multimeric assembly of $\operatorname{Cav} \alpha 1, \operatorname{Cav} \alpha 2 \delta$, and $\operatorname{Cav} \beta$ subunits to form a functional complex [17]. Moreover, these channels all interact constitutively with calmodulin [78]. In addition to their more depolarized range of activation, they are distinguished from LVA channels by their larger single channel conductance and open probability, which allow these channels to support large calcium influxes at depolarized potentials. Indeed, it has been estimated that a single HVA calcium channel will increase internal calcium from a resting value of $70-100 \mathrm{nM}$ to greater than $40 \mu \mathrm{M}$ within a millisecond $15 \mathrm{~nm}$ distant from the channel pore [85].

LVA channels encompass the family of T-type calcium channels [97]. These channels are comprised of just a Cav $\alpha 1$ subunit and thus unlike HVA channels do not require assembly with ancillary subunits to replicate native currents. The Cav3 $\alpha 1$ subunit is comprised of four major transmembrane domains that are connected by large cytoplasmic linker regions [97] (Fig. 1a). N- and C-termini are also located on the cytoplasmic side, with sequence variation in the $\mathrm{C}$-terminus or internal linkers being a characteristic delimiter between the
Cav3 channel isoforms. All three members of this family (Cav3.1, Cav3.2, and Cav3.3) share a small single channel conductance, rapid activation and inactivation kinetics, and relatively slow deactivation, the latter giving rise to more prolonged calcium influx through tail currents [84]. Furthermore, due to their specific voltage dependencies of activation and inactivation, Cav3 channels give rise to a window current that allows these channels to be tonically active at typical neuronal resting membrane potentials [21, $25,29,31,33,34,51]$. The voltage range for window current varies between cells but can be anywhere from -90 to $+20 \mathrm{mV}$ $[31,33,34,118,121]$. The fact that these channels can be tonically active at rest allows them to contribute to functions that range from low threshold exocytosis $[136,137]$ to spikeactivated inward current [118]. Because Cav3 channels are partially inactivated at rest, a membrane hyperpolarization can recover channels from inactivation, giving rise to larger T-type currents during a subsequent depolarization that can directly regulate neuronal firing properties [7, 25, 33, 51, 81, 142]. As we will discuss in this review, $\mathrm{Cav} 3$ channels also prove to act as the source of calcium for several different types of potassium channels, thereby supporting an indirect but important means of regulating neuronal firing behavior that was only recently recognized.

\section{Calcium-gated potassium channels}

$\mathrm{KCa} 1.1$ and $\mathrm{KCa} 2 . \mathrm{x}$ potassium channels have been traditionally recognized as those gated by calcium entry to control membrane excitability in central neurons $[1,12,129,135]$. The properties of KCa1.1 and KCa2.x channels differ in key respects that support fine-tuned roles in mediating spike repolarization and afterhyperpolarizations (AHPs) over relatively short time frames of activity $[1,66,67,85,116,123,133]$. All three $\mathrm{KCa} 2 . \mathrm{x}$ channel isoforms (KCa2.1-3; SK1-3; KCNN1-3) [1, $12,135]$ are purely calcium dependent due to the association of calmodulin with the C-terminal region $[1,57,58,63,141]$. While Cav3 calcium channels have been shown to at least functionally couple to $\mathrm{KCa} 2$.x channels $[26,138]$, we will not focus on this given the lack of protein biochemical evidence for a potential ion channel complex at this time.

\section{KCa1.1}

KCa1.1 channels are similar to voltage-gated potassium channels in activating in response to membrane depolarization; however, the voltage dependence of activation is strongly regulated by cytosolic free calcium concentration [28]. KCa1.1 channels are formed by the association of four identical pore forming $\alpha$-subunits plus ancillary $\beta$-subunits which coassemble with the $\alpha$-subunit in a 1:1 fashion. The $\alpha$-subunit 
a

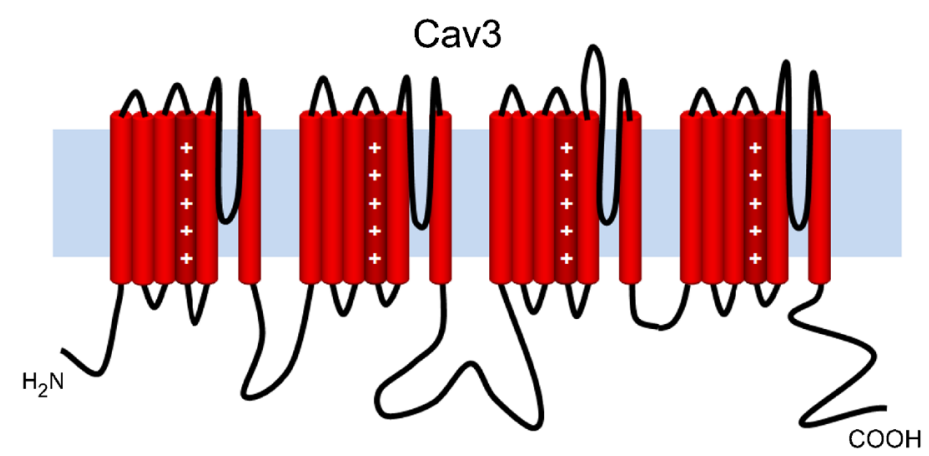

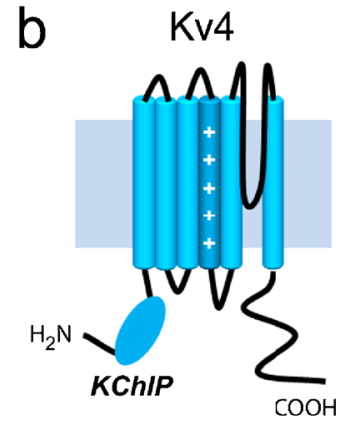

Fig. 1 Transmembrane topology of the Cav3 $\alpha 1$ subunit and the three types of potassium channel subunits discussed in this review. a Cav3 channels are comprised of four homologous transmembrane domains that are connected via large cytoplasmic linkers. Each of these domains contains six-membrane spanning helices plus a re-entrant pore loop. Voltage sensors are formed by positive charges on the fourth transmembrane helix in each domain. b Potassium channel subtypes recognized to form ion signaling complexes with Cav3 calcium channels. Kv4 channels are similar to a single domain of Cav3 channels, and four of these

contains seven membrane spanning helices ( $\mathrm{S} 0$ to $\mathrm{S} 6$ ), with an extracellular N-terminus and an intracellular C-terminus [28] (Fig. 1b). The C-terminus contains a "regulating conductance of potassium" (RCK) domain and a calcium bowl to confer calcium sensitivity onto KCa1.1 channel activation [32, 43, $46,82,102,111]$. The affinity of the calcium binding site on KCa1.1 channels is substantially lower than that of calmodulin associated with $\mathrm{KCa} 2 . \mathrm{x}$ and $\mathrm{KCa} 3.1$ channels, with reported minimal intracellular calcium concentrations necessary for activation ranging from 1 to $>10 \mu \mathrm{M}[12,85,123]$. As a result KCa1.1 channels are typically activated by relatively large voltage responses such as spike discharge, thereby contributing to spike repolarization and a fast AHP (fAHP) [85, 115, 139]. Previous studies have shown that KCa1.1 channels can form signaling complexes with HVA channels, thereby localizing the channels close to the source of calcium entry [10, 11 , $45,85]$, but the underlying channel structural determinants are unknown. Indeed, all of Cav1.2 (L), Cav2.1 (P), and Cav2.2 (N) channels can form what were proposed as supercomplexes with KCa1.1 channels, although not with the Cav2.3 calcium channel isoform $[10,12]$. The functional importance of this interaction has been repeatedly established, such that blockade of HVA calcium channels (and hence, indirectly, the activity of KCa1.1 channels) in neurons results in drastic alterations of intrinsic neuronal firing properties [109, 112, 115, 117, 139]. New data summarized below now indicates that LVA Cav3 calcium current also has an important role in activating KCa1.1-mediated outward current.

\section{KCa3.1}

KCa3.1 channels are a third class of calcium-gated potassium channel that belong to the same gene family as $\mathrm{KCa} 2 . \mathrm{x}$ channels but share only $45 \%$ protein sequence homology $[52,57,72,135]$. KCa3.1 channels are also only calcium dependent through the association with calmodulin [37, 40, $52,57,72,96,105,106,113]$ but activate and deactivate over a much longer time frame (up to seconds) than $\mathrm{KCa} 1.1$ or KCa2.x channels $[50,68,69,126]$. KCa3.1 channels are derived from a single gene (KCNN4) with virtually all $\mathrm{KCa} 3.1$ channels sequenced from various body tissues (i.e., pancreas, placenta, lymphocytes) sharing an equivalent sequence $[52,57,72]$. KCa3.1 channels have a sixtransmembrane domain structure and intracellular N- and Ctermini (Fig. 1b). The proximal $\mathrm{C}$-terminus contains a 
constitutive binding site for calmodulin [58] with an $\mathrm{IC}_{50}$ for calcium from 95 to $300 \mathrm{nM}$ compared to $\sim 300-500 \mathrm{nM}$ for $\mathrm{KCa} 2 . \mathrm{x}$ channels $[1,57]$, making $\mathrm{KCa} 3.1$ channels potentially more sensitive to changes in internal calcium concentration.

The expression pattern and properties of $\mathrm{KCa} 3.1$ channels have been extensively examined outside the CNS, where KCa3.1 channels are expressed in red blood cells [41], endoand epithelial cells $[8,39,48,119,130,132]$, lymphocytes $[42,61]$, and glia $[19,60,61,71]$. The function of KCa3.1 channels in controlling neuronal excitability has been best characterized in enteric neurons, where $\mathrm{KCa} 3.1$ channels generate a slow AHP (sAHP) of seconds duration [91, 92, 128]. However, in central regions, KCa3.1 channels were not believed to be expressed in neurons $[52,53,72]$ but instead were restricted to endothelial cells and activated glia $[9,53,124$, 140]. Nevertheless, reports suggesting the expression of KCa3.1 channels in more central neurons exist, with molecular, immunocytochemical, or electrophysiological data reported in sensory cells of peripheral and autonomic nervous systems $[39,83,90,92,127]$ as well as motor neurons [13, 83]. Most recently, KCa3.1 channel expression in a central neuron was established for the first time in cerebellar Purkinje cells [34], raising questions as to how widespread $\mathrm{KCa} 3.1$ channel expression may be in other central regions. Moreover, the first study examining KCa3.1 channels in Purkinje cells revealed the presence of a Cav3-KCa3.1 complex with important functional roles [34].

\section{Voltage-gated A-type potassium channels}

Among the myriad of voltage-gated potassium channels are a small subset of channels that are activated from a low membrane voltage and in a transient fashion to trigger "A-type" currents. In central regions, A-type potassium currents are often generated by members of the Kv4 channel family (Kv4.1-4.3; KCND1-3) [54, 108]. As found for Cav3 calcium channels, Kv4 channels exhibit a low voltage for activation, fast inactivation, near-complete inactivation at resting potential, and an availability that is governed by preceding membrane hyperpolarizations [54]. Kv4 channels share the common structure of potassium channels in being comprised of four $\alpha$-subunits containing six transmembrane domains, an $\mathrm{S} 4$ voltage-sensing domain, and intracellular $\mathrm{C}$ - and $\mathrm{N}$-termini (Fig. 1b). All structural indices then suggest that Kv4 channels belong entirely to the class of voltage-gated channels. However, reports as early as the 1980 s began to suggest that A-type potassium channels may also be regulated by calcium influx, although the mechanism was never resolved [14, 18, $74,107,143]$. Kv4 channels were subsequently found to link to "potassium channel interacting proteins" (KChIP1-4; Fig. 1b), a class of calcium sensor molecules that affect channel translocation and kinetic properties $[3,15,62,94$,
98, 104, 110, 131]. A second auxillary subunit termed dipeptidyl peptidase-like proteins (DPPs) was identified as membrane spanning proteins that directly interact with the Kv4 $\alpha$-subunit [30, 38, 54, 56, 59, 87, 88, 99, 103]. While DPPs also exert important effects on baseline properties of $\mathrm{Kv} 4$ channels, there is no evidence to date for a role in mediating calcium-dependent effects. The combination of Kv4 $\alpha$-subunits together with KChIP and DPP proteins together is now recognized as comprising the "Kv4 complex" $[22,24,55,59,75,86]$.

The presence of KChIP molecules as part of the Kv4 complex signifies the presence of a very different form of calcium sensor than those inherent to $\mathrm{KCa} 3.1$ or $\mathrm{KCa} 1.1$ channels. Here, four KChIP molecules bind to the Kv4 $\alpha$ subunit N-termini to form a "cross-shaped octomer" on the cytoplasmic side to bind calcium [98, 131]. KChIPs1-4 are derived from separate genes and belong to the larger family of calcium sensor proteins that contain four EF-hand domains on the C-terminus [15, 73]. EF-1 does not bind calcium and EF-2 is bound to magnesium, leaving EF-3 and EF-4 as potential calcium binding sites. The dissociation constant for calcium binding to EF-3 and EF-4 is $5 \mu \mathrm{M}$ [95] and therefore midrange in sensitivity to $[\mathrm{Ca}]_{\mathrm{i}}$ from that of calmodulin $(<300 \mathrm{nM})$ or KCa1.1 RCK domains $(1-10 \mu \mathrm{M})$. Although KChIP proteins were identified as a mechanism to provide calcium-dependent regulation of Kv4 current, the effects of calcium influx on $\mathrm{KChIPs}$ and Kv4 current were not subsequently reported. The potential source of calcium that might activate KChIPs also remained unknown. As elaborated below, recent work reveals that Cav3 calcium channels selectively associate with the Kv4 complex to modulate A-type current in a KChIP3-dependent manner $[4,5]$.

\section{Cav3 interactions with potassium channels}

\section{Cav3.2-KCa3.1 complex}

A recent study on the ionic basis for a sAHP that follows parallel fiber-evoked excitatory postsynaptic potentials (EPSPs) in rat cerebellar Purkinje cells came to the conclusion that KCa3.1 channels were in fact expressed in these cells and activated by forming a complex with Cav3.2 calcium channels [34]. Thus, dual immunocytochemistry revealed $\mathrm{KCa} 3.1$ in the somatic region of Purkinje cells and on isolated segments of primary dendrites of these cells (Fig. 2a-c). Moreover, KCa3.1 immunolabel was strongly colocalized with that of Cav3.2 in both somatic and dendritic locations (Fig. 2c). The validity of the immunolabel was supported by RT-PCR in which KCa3.1 signal was detected on Western blots from lysates of whole cerebellum as well as cytoplasmic extracts obtained through whole-cell patch recordings in vitro to conduct single-cell RT-PCR (Fig. 2d). Important controls 

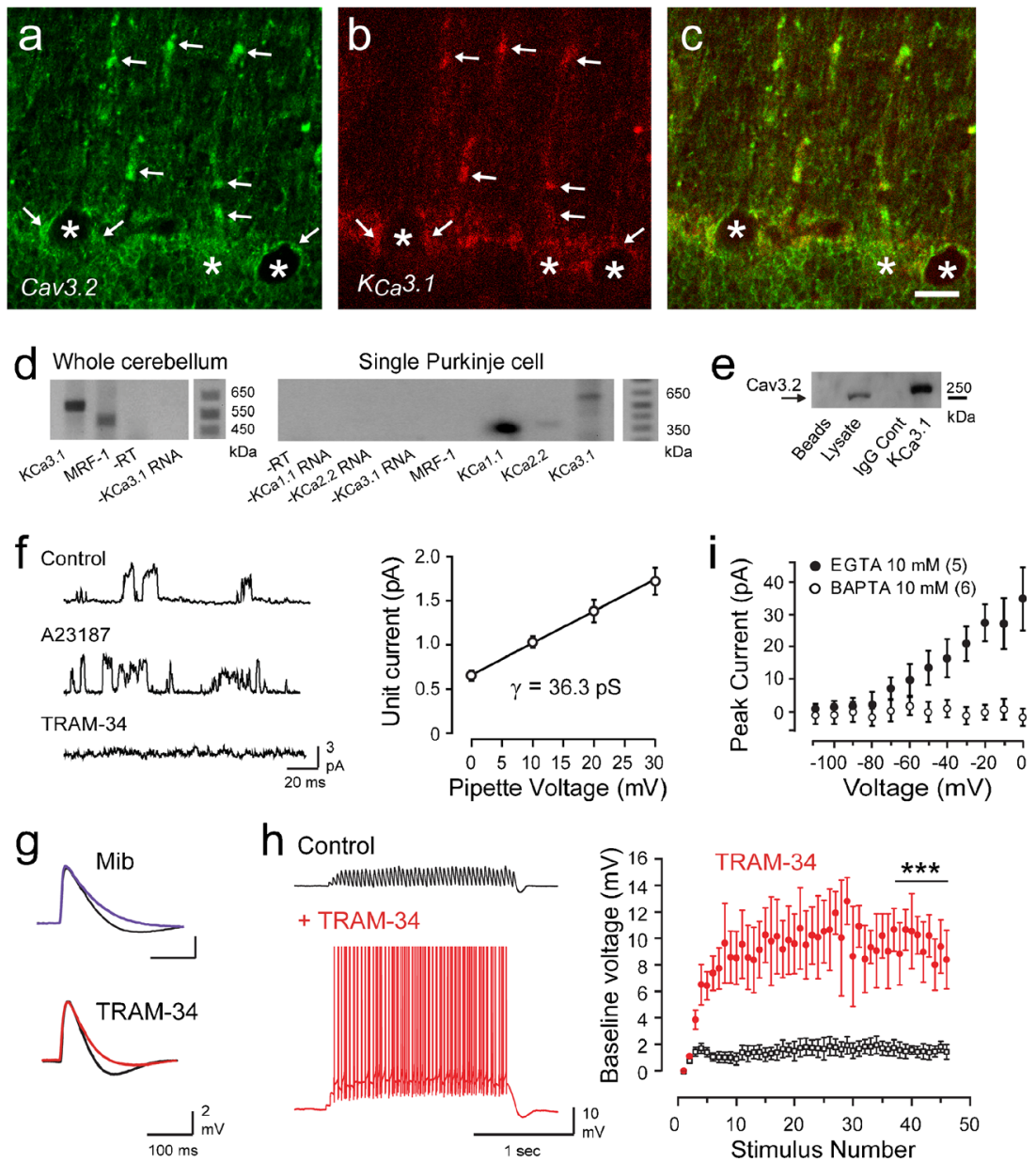

Fig. 2 Cav3 calcium channels associate with $\mathrm{KCa} 3.1$ channels to regulate temporal summation of EPSPs. a-c Dual-label immunocytochemistry for Cav3.2 (a) and $\mathrm{KCa} 3.1$ (b) reveals protein colocalized (arrows) at the soma (asterisks) and restricted segments of dendrites (c). d RT-PCR reveals KCa3.1 and MRF-1 mRNA in the whole cerebellum (left) and $\mathrm{KCa} 1.1, \mathrm{KCa} 2.2$, and $\mathrm{KCa} 3.1$ but not MRF-1 in single Purkinje cell cytoplasmic extracts $(r i g h t)$. e KCa3.1 protein coimmunoprecipitates with Cav3.2 from rat cerebellar lysate. f On-cell channel recordings $(+30-\mathrm{mV}$ pipette potential) before and after perfusing the calcium ionophore A23187 $(2 \mu \mathrm{M})$ and blocked by TRAM-34 (100 nM). Plot of mean single channel amplitudes at steady-state potentials up to $+30 \mathrm{mV}$ reveals a mean conductance of $36.3 \mathrm{pS}(n=5)$. g Injection of simEPSCs in Purkinje cells reveals that the simEPSP rate of decay is reduced by mibefradil $(1 \mu \mathrm{M})$ and TRAM-34 $(100 \mathrm{nM})$. h Recordings and plots of the baseline membrane voltage during $25-\mathrm{Hz}$ trains of parallel fiberevoked EPSPs and TRAM-34 perfusion show that IKCa channels suppress temporal summation of EPSPs and repetitive spike output. i Mean values of TRAM-sensitive current in outside-out patches reveal a block of the Cav3-IKCa interaction with internal BAPTA but not EGTA. Scale bar in (a-c) $20 \mu \mathrm{m}$. Mean \pm SEM; $* * * p<0.001$. Abbreviation: Mib mibefradil. Modified from [34]

current amplitude over a series of on-cell pipette voltage steps revealed that the single channel conductance was $\sim 36 \mathrm{pS}$, a value consistent with that previously reported for $\mathrm{KCa} 3.1$ channels (Fig. 2f) [52].

The physiological role for $\mathrm{KCa} 3.1$ channels became apparent when simulated EPSCs (simEPSCs) were used to evoke simulated EPSPs (simEPSPs) at the level of Purkinje cell somata to test the role of postsynaptic ion channels in generating a synaptic response [34]. Applying either mibefradil to block Cav3 calcium entry or TRAM-34 to block KCa3.1 channels produced an equivalent block of the decay phase of the simEPSP in Purkinje cells (Fig. 2g). By comparison, none of the established blockers for HVA calcium channels, $\mathrm{KCa}$ 2. $\mathrm{x}$ channels, or $\mathrm{KCa} 1.1$ channels could reproduce these 
effects. When a train of subthreshold simEPSPs was applied at $25 \mathrm{~Hz}$, it was found that temporal summation of EPSPs was strongly suppressed beyond the first four to five stimuli but that consistent and continual spike discharge was evoked when TRAM-34 was applied to block KCa3.1 channels (Fig. 2h). Importantly, TRAM-34 was also effective in the presence of picrotoxin used to block feedforward inhibitory projections activated by parallel fibers [79], indicating that both systems serve to regulate EPSP summation. KCa3.1 channel activation by Cav3 calcium influx could thus be traced to suppressing the baseline EPSP-membrane voltage response during repetitive synaptic input, acting as a high-pass filter to suppress background parallel fiber synaptic activity under normal conditions.

The link between Cav3.2 calcium influx and KCa3.1 activation was all supported by the close association indicated through coimmunoprecipitation and immunocytochemistry. To further assess the distance between the two channels in the complex, we employed the use of the two calcium chelator EGTA and BAPTA. Here, it was shown in outside-out patch recordings that TRAM-34-sensitive outward current was present when $10 \mathrm{mM}$ EGTA was included in the electrode but not in the presence of $10 \mathrm{mM}$ BAPTA (Fig. 2i). This was important in establishing that the Cav3-KCa 3.1 complex functions at the level of a calcium nanodomain or $<50-\mathrm{nm}$ distance [36]. The exact sites that form a link between Cav3.2 and $\mathrm{KCa} 3.1$ have not yet been identified nor has the degree to which these findings extend to Cav3.1 or Cav3.3. Yet taken together, these data argue strongly for the first nanodomain interaction between Cav3 calcium channels and a calciumactivated potassium channel.

\section{Cav3.2-KCa1.1 complex}

A second interaction between Cav3 channels and a calciumactivated potassium channel was recently reported for $\mathrm{KCa} 1.1$ channels [101]. Here, the relationship between Cav3 calcium influx was examined through expression of cDNAs in tsA201 cells and in cells of the rat medial vestibular nucleus $(\mathrm{MVN})$ maintained as an in vitro slice preparation. Coexpressing cDNAs for human Cav3.2 and KCa1.1 in tsA201 cells revealed that while a voltage command pulse delivered from a value of -100 to $+40 \mathrm{mV}$ did not reliably activate $\mathrm{KCa} 1.1$ current, preceding this pulse with a step to $-30 \mathrm{mV}$ to maximally activate Cav3 current augmented KCa1.1 current (Fig. 3a). The mechanism for KCa1.1 activation was apparent in $I-V$ plots where a Cav3 calcium prepulse left-shifted the voltage dependence for $\mathrm{KCa} 1.1$ activation, a result expected due to the interplay between calcium- and voltage-gated activation of $\mathrm{KCa} 1.1$ channels. Corroboration of the role for Cav3-mediated calcium influx was obtained when expressing KCa1.1 cDNA with a Cav3.2 pore mutant that does not conduct calcium (Cav3.2pm) prevented the leftward shift in
KCa1.1 voltage for activation (Fig. 3a). Notably, the Cav3mediated effect proved to be sensitive to block not only by internal perfusion of BAPTA but also by as little as $5 \mathrm{mM}$ EGTA (Fig. 3b), the implications of which are discussed further below.

Protein biochemical tests revealed that Cav3.2 channels coimmunoprecipitate with $\mathrm{KCa} 1.1$ from lysates of either the brain or cerebellum (Fig. 3c) and from lysates of tsA-201 cells expressing only the channel $\alpha$-subunits (Fig. 3d). Further tests for coimmunoprecipitation between Cav3.2 and different KCa1.1 mutant channels further narrowed down the site for interaction. Thus, Cav3.2 channels coimmunoprecipitated with a mutant construct comprised of only the KCa1.1 Nterminus and $\mathrm{S} 0$ transmembrane segment $(\mathrm{N}+\mathrm{S} 0)$, with a naturally occurring truncated $\mathrm{N}$-terminal variant with $\mathrm{SO}$ $(\mathrm{aN}+\mathrm{S} 0)$, but not with a construct comprised of only the longer N-terminus (Fig. $3 \mathrm{~d}$ ). These data strongly implicate a site of interaction between Cav3.2 and the transmembrane S0 segment.

Previous work had reported at least a functional coupling between $\mathrm{Ni}^{2+}$-sensitive calcium influx and KCa1.1 in MVN cells [111]. However, direct biophysical tests of the nature of this activation had not been reported. We used whole-cell voltage clamp of MVN cells in vitro to examine $\mathrm{KCa} 1.1$ current isolated by either paxilline $(1 \mu \mathrm{M})$ or TEA $(1 \mathrm{mM})$ application and compared these to outward currents isolated by perfusing the Cav3 blockers mibefradil $(1 \mu \mathrm{M})$ or $\mathrm{Ni}^{2+}$ $(300 \mu \mathrm{M})($ Fig. 3e) [101]. In each case the isolated current was fast activating and slowly inactivating over the time of a 200$\mathrm{ms}$ step command to $+40 \mathrm{mV}$ (Fig. 3e). Using a ramp command over a -100 to $-30 \mathrm{mV}$ range with paxilline or mibefradil treatment further revealed LVA outward current that activated just subsequent to LVA inward calcium current, indicating that Cav3 calcium influx can activate $\mathrm{KCa} 1.1$ above $\sim-70 \mathrm{mV}$ (Fig. 3f). Finally, applying mibefradil to MVN cells under current clamp slowed spike repolarization, reduced a subsequent fAHP (Fig. 3g), and increased the gain of firing, revealing that the Cav3-KCa1.1 interaction normally reduces spike output in MVN cells. These data were entirely novel in identifying a new association between Cav3 and $\mathrm{KCa} 1.1$ channels in an ion channel complex, helping account for earlier reports of the role for $\mathrm{KCa} 1.1$ in controlling gain in MVN cells $[89,111]$.

\section{Cav3-Kv4 complex}

A series of recent studies on stellate cell interneurons in the cerebellum led to a new understanding of how Cav3 channels can interact with even voltage-gated potassium channels. Earlier work on the expression pattern of Cav3 channel isoforms in these cells [77] led to the finding that membrane hyperpolarizations expected to promote a rebound increase in firing frequency instead promoted a unique voltage-dependent 

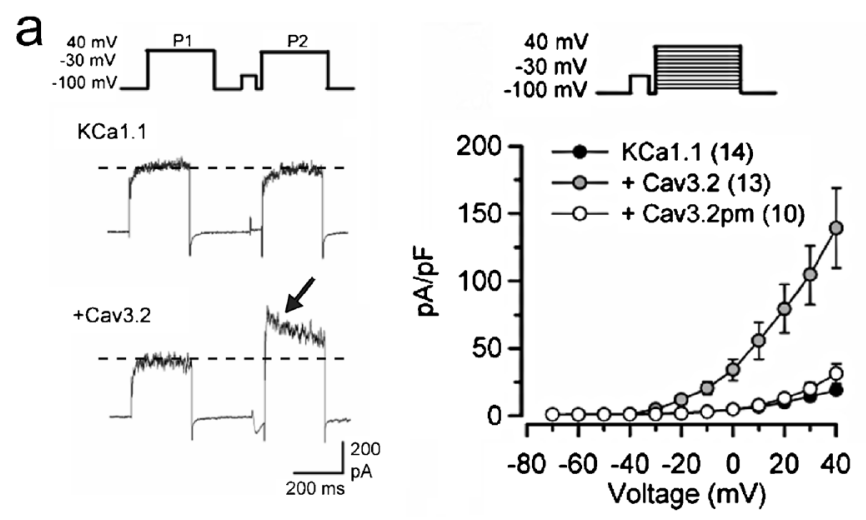

b $\quad$ Cav3.2 + KCa1.1
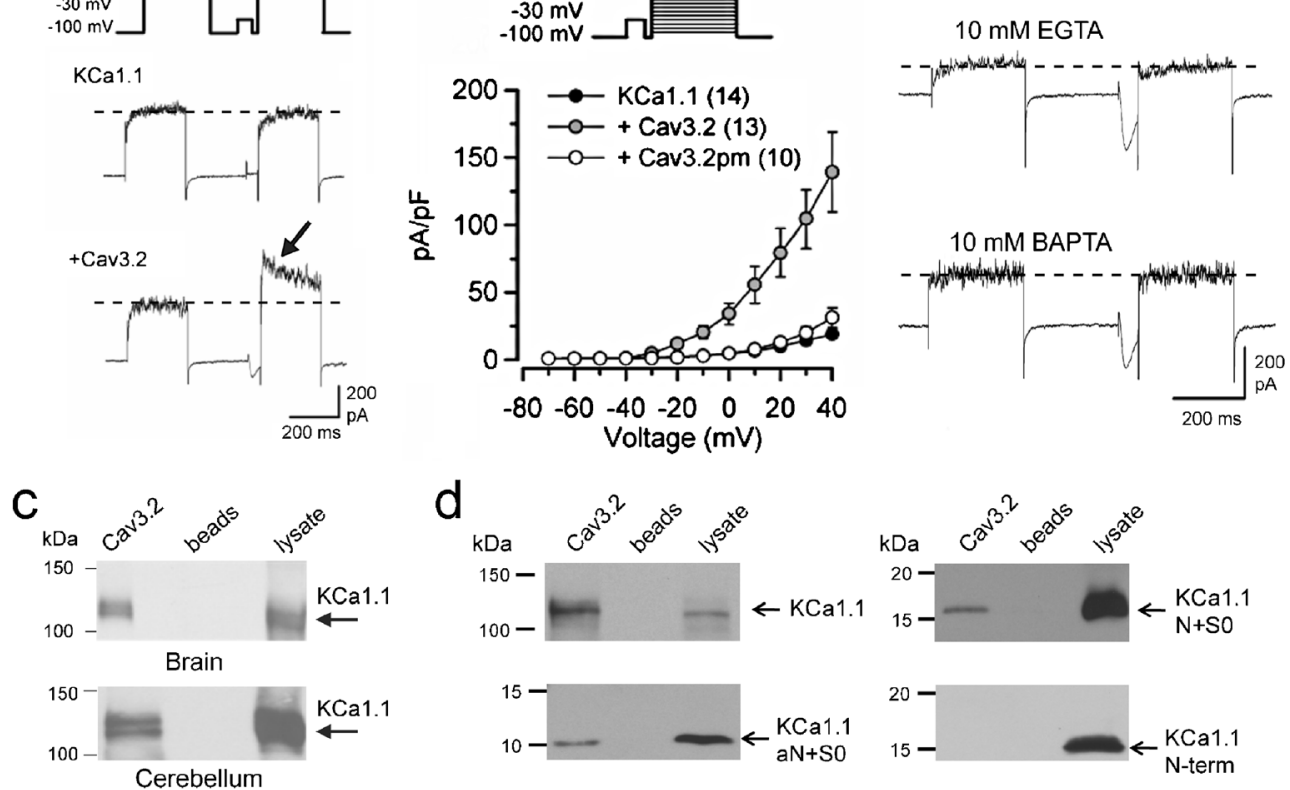

e
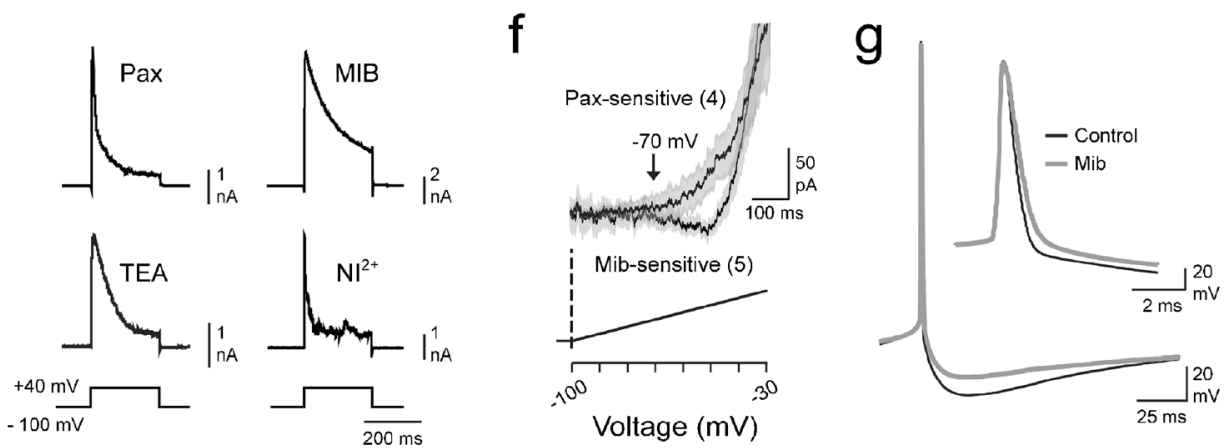

Fig. 3 A Cav3.2-KCa1.1 channel complex generates a LVA KCa1.1 current involved in spike repolarization and a fAHP. a Whole-cell patch recordings from tsA-201 cells expressing KCa1.1 and/or Cav3.2 cDNA reveal that Cav3.2 calcium influx triggered by a prepulse command augments KCa1.1 current (arrow). Steps: $250 \mathrm{~ms},+40 \mathrm{mV}$; prepulse $50 \mathrm{~ms},-30 \mathrm{mV}$, return $2 \mathrm{~ms}$. Plots of mean current for $\mathrm{KCa} 1.1$ expressed alone, with Cav3.2, or a noncalcium-conducting Cav3.2 pore mutant (Cav3.2pm). b KCa1.1 current augmentation by Cav3 calcium influx during a step prepulse in tsA-201 cells is blocked by internal EGTA or BAPTA. c Cav3.2 and KCa1.1 proteins coimmunoprecipitate from lysates of the rat brain or cerebellum. d Lysates from tsA-201 cells reveal

shift in first spike latency [80]. As ionic control of first spike latency has traditionally been assigned to A-type potassium channels, it prompted further investigation into how Cav3 channels might influence this important aspect of spike firing dynamics. It was finally concluded that the coexpression of $\mathrm{Cav} 3$ and $\mathrm{Kv} 4$ channels led to a non-monotonic profile in the voltage-first spike latency profile, with Cav3 calcium influx reducing latency from more hyperpolarized potentials, and Kv4 current increasing spike latency from membrane potentials near rest [80]. However, there was a curious peak in the voltage-latency profile near resting membrane potential that proved to be sensitive to Cav3 channel blockers, implying that Cav3 and Kv4 channels may establish first spike latency that Cav3.2 coimmunoprecipitates with full-length $\mathrm{KCa} 1.1, \mathrm{~N}+\mathrm{S} 0$, and $\mathrm{aN}+\mathrm{S} 0$, but not the $\mathrm{KCa} 1.1 \mathrm{~N}$-terminus expressed in isolation. Western blots reflect myc-tagged KCa1.1 channels or their fragments. e Wholecell currents in MVN cells isolated as paxilline $(1 \mu \mathrm{M})$ - or TEA $(1 \mathrm{mM})$ sensitive $\mathrm{KCa} 1.1$ current compared to currents isolated as mibefradil $(1 \mu \mathrm{M})$ - or $\mathrm{Ni}^{2+}(300 \mu \mathrm{M})$-sensitive (Cav3-activated) currents. f Average plots of currents in MVN cells isolated by either paxilline $(1 \mu \mathrm{M})$ or mibefradil $(1 \mu \mathrm{M})$ during ramp commands (SEM values shaded). $\mathbf{g}$ Mibefradil $(1 \mu \mathrm{M})$ slows spike repolarization and reduces the fAHP in a MVN cell. Mean \pm SEM. Abbreviations: Mib mibefradil, pax paxilline. Modifed from [101]

characteristics by interacting at a level beyond simple coexpression in the membrane.

Further studies on this potential interaction departed from the standard procedure of blocking all calcium influx when isolating potassium channels and found that under conditions of blocking sodium and HCN channels, the prominent current recorded was a transient Kv4 A-type response (Fig. 4a) [4]. However, blocking Cav3 calcium influx with mibefradil $(0.5 \mu \mathrm{M})$ revealed a select leftward shift in the voltageinactivation profile for $\mathrm{Kv} 4$ current $\left(V_{\mathrm{h}}\right)$ without any effect on the voltage for activation (Fig. 4b). Importantly, these effects were not due to direct effects on the channel, as no such influence was detected on $\mathrm{Kv} 4$ channels expressed in 
a
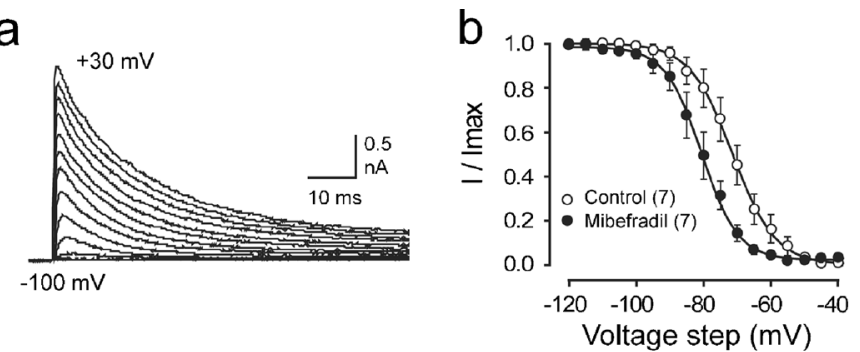

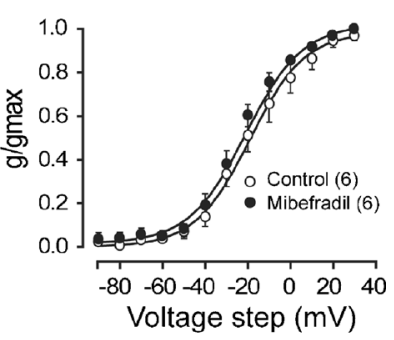

C
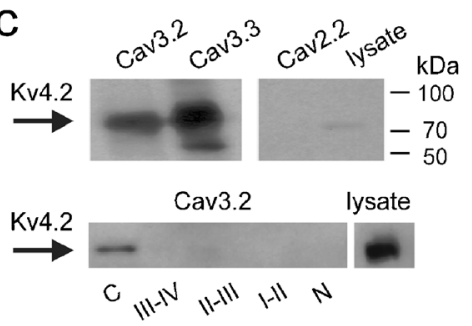

d tsA-201 cells
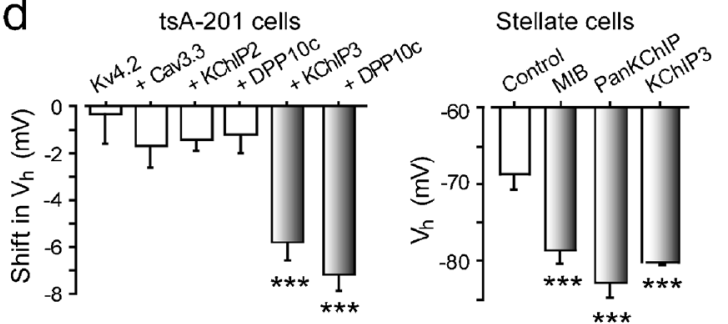

e
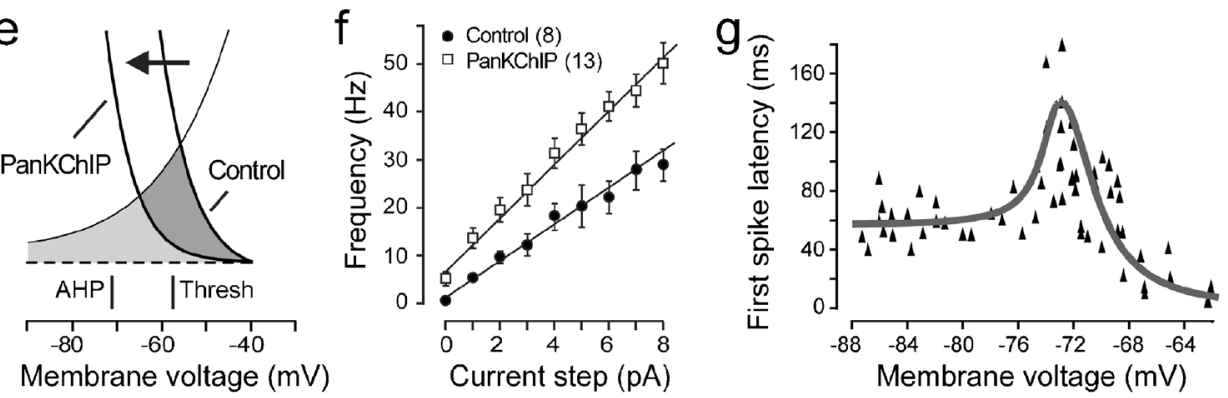

Membrane voltage $(\mathrm{mV})$

Current step $(\mathrm{pA})$

Membrane voltage $(\mathrm{mV})$

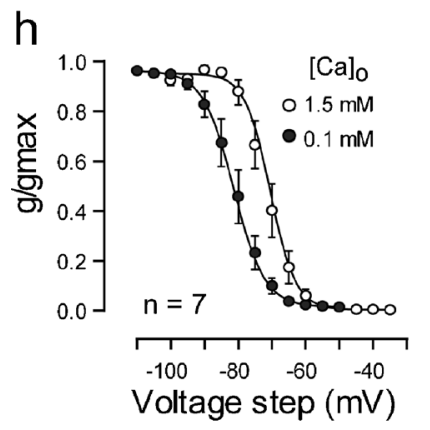

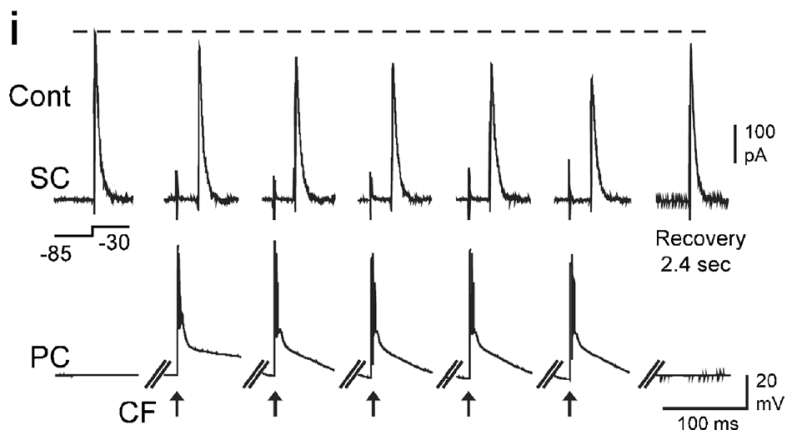

Fig. 4 A Cav3-Kv4 complex in stellate cells regulates $I_{\mathrm{A}}$ availability near rest and acts as an extracellular calcium sensor. a Whole-cell voltage clamp of $I_{\mathrm{A}}$ in cerebellar stellate cells in the absence of calcium channel blockers. b Blocking Cav3 calcium influx with mibefradil $(0.5 \mu \mathrm{M})$ selectively left-shifts the voltage-inactivation plot $\left(V_{\mathrm{h}}\right) \sim-10 \mathrm{mV}$ without affecting voltage for activation. $\mathbf{c} \mathrm{Kv} 4.2$ channel coimmunoprecipitates with Cav3.2 or Cav3.3 protein but not Cav2.2 from rat brain lysate (top row) and pulls down with the C-terminus of Cav3 GST fusion proteins (bottom row). d Coexpressing different $\mathrm{Kv} 4$ complex members in tsA201 cells reveals a critical role for KChIP3 in mediating a mibefradilinduced shift in Kv4 $V_{\mathrm{h}}(l e f t$ ). Internal perfusion of PanKChIP or KChIP3 antibodies into stellate cells selectively disrupts the Cav3-Kv4 complex function to induce the same shift in $V_{\mathrm{h}}$ as mibefradil (right). e Magnified

isolation in tsA-201 cells. Protein biochemical studies on Cav3.2 and Cav3.3 channel isoforms (those inherently expressed in stellate cells) further established that Cav3 (but not Cav2.2) proteins coimmunoprecipitated with Kv4.2 from view of the foot of $\mathrm{Kv} 4$ activation and inactivation plots indicating that a leftward shift in $V_{\mathrm{h}}$ (arrow) by dialyzing a PanKChIP antibody reduces window current in the region of spike threshold. $\mathbf{f}, \mathbf{g}$ Plots showing the role of the Cav3-Kv4 complex in normally reducing firing rate gain (f) and increasing first spike latency near resting potential (g) in stellate cells in response to current pulse injections. $\mathbf{h}$ Dependence of the Cav3-Kv4 complex function on calcium influx enables sensitivity to decreases in $[\mathrm{Ca}]_{\mathrm{o}}$. Test pulse $-30 \mathrm{mV}$. i Dual recordings of $I_{\mathrm{A}}$ in a cerebellar stellate cell and complex spike discharge in a Purkinje cell directly below the stellate cell recording. Repetitive $10-\mathrm{Hz}$ CF stimulation and complex spike discharge is associated with a decrease in $I_{\mathrm{A}}$ (dashed line). Mean \pm SEM; Abbreviations: Thresh threshold, $S C$ stellate cell, $P C$ Purkinje cell, $C F$ climbing fiber. $* * * p<0.001$. Modified from $[4,6,80]$ brain lysates (Fig. 4c). Moreover, Kv4.2 channels selectively pulled down with the $\mathrm{C}$-terminal region of Cav3.2 or Cav3.3 channels among a set of glutathione $S$-transferase (GST) fusion proteins of each of the internal Cav3 channel linkers and 
C- and N-termini expressed in tsA-201 cells (Fig. 4c). These results are important in establishing that $\mathrm{Kv} 4.2$ channels form a direct molecular association with the $\mathrm{C}$-terminal region of Cav3 channels. In fact, subsequent work established that this link can be detected between all $\mathrm{Kv} 4$ isoforms and all Cav3 channel isoforms [5]. In further characterizing the basis for Cav3-Kv4 function, different combinations of Kv4 complex subunits were expressed in tsA-201 cells to identify the minimal complement necessary to reproduce a mibefradil-induced shift in Kv4 $V_{\mathrm{h}}$. This work showed that expressing a Cav3 and $\mathrm{Kv} 4$ channel isoform is necessary but that the KChIP3 isoform is necessary and sufficient as an accessory protein to account for calcium-dependent regulation of Kv $4 V_{\mathrm{h}}$ (Fig. 4d) [4]. By comparison, none of the HVA calcium channels (P/Q-, $\mathrm{N}$-, L-, or R-type) or other KChIP isoforms were able to modulate Kv4 current when tested in tsA-201 cells. These data are important in showing that only the Cav3 calcium channel can associate with the $\mathrm{Kv} 4$ channel complex to confer calcium-dependent control through the specific calcium sensing action of KChIP3.

A series of studies established that infusing either a KChIP3 or PanKChIP antibody through the electrode (1:100 dilution) during stellate cell recordings mimicked the effects of applying mibefradil in left-shifting Kv4 $V_{\mathrm{h}}$ (Fig. 4d), providing the first means of interfering with Cav3-Kv4 complex function. With this tool in hand, one could test the functional role of a Cav3-Kv4 complex, with antibody infusion revealing that a Cav3 calcium-mediated rightward shift in the voltageinactivation profile ordinarily acts to increase $\mathrm{Kv} 4$ window current in the region of spike threshold (Fig. 4e). As a result, the Cav3-Kv4 complex reduces cell excitability, as measured by a significant drop in firing rate gain (Fig. 4f) [4]. A Cav3mediated increase in Kv4 window current near rest also accounted for the increase in the voltage-first spike latency relationship that was identified in stellate cells near resting potentials (Fig. 4g) [80]. While repetitive stimulation to increase internal calcium concentration is without apparent effect on Kv4 availability, the Cav3-Kv4 complex proves to be highly sensitive to decreases in extracellular calcium levels (Fig. 4h) [6]. This is important because it has been established that physiological rates of excitatory afferent input to the cerebellum rapidly decrease extracellular calcium concentration in the order of $30 \%$ from resting values $[49,93,114]$. We thus used dual recordings between a Purkinje cell and a stellate cell directly above in the molecular layer to assess the effects of climbing fiber stimulation on $I_{\mathrm{A}}$ and $I_{\mathrm{T}}$ [6]. As shown in Fig. 4i, $I_{\mathrm{A}}$ was isolated pharmacologically while recording from a Purkinje cell under current clamp to monitor complex spike discharge. Repetitive complex spike discharge at $10 \mathrm{~Hz}$ rapidly decreased $I_{\mathrm{A}}$ amplitude, with full recovery within $2-3 \mathrm{~s}$ after the end of a stimulus train. Similarly, climbing fiber stimulation decreased $I_{\mathrm{T}}$ in stellate cells during a stimulus train, with even faster kinetics of recovery (data not shown). Since the decrease in $I_{\mathrm{A}}$ availability increased the firing rate gain of stellate cells, it was found that the Cav3$\mathrm{Kv} 4$ complex functions to provide adaptive inhibitory control over Purkinje cells in the face of excitatory afferent-induced reductions in extracellular calcium [6]. These findings were key in establishing that expression of the Cav3-Kv4 complex in stellate cells ultimately underlies a new form of homeostatic control over circuit function [6].

\section{Microdomain versus nanodomain interactions}

Given widely different calcium sensors and potassium channels involved in these ion channel complexes, it is interesting to compare the relative efficacy of Cav3 calcium channels to effect potassium channel activation. Previous work has shown that calcium influx gives rise to a domain of decreasing internal calcium surrounding the internal pore of the channel. The distance over which calcium influx can trigger a calciumdependent event is distinguished by those functioning at the level of a calcium microdomain (50-200-nm distance) or a nanodomain $(<50 \mathrm{~nm})$ [36]. It is known that interactions between the HVA calcium channels Cav2.1 or Cav2.2 and $\mathrm{KCa} 1.1$ in an expression system occur at the level of a nanodomain [11]. The ability for HVA calcium influx to activate $\mathrm{KCa} 1.1$ is such that even the voltage dependence and kinetics of either calcium channel subtype is imparted upon KCa1.1 activation. Given that all of the complexes reviewed here share Cav3 channels as a common partner, key factors that could be predicted to control the degree of potassium channel activation would be (1) the relative proximity of calcium and potassium channels, (2) the sensitivity of the calcium sensors to changes in internal calcium, and (3) the relative conductance of Cav3 calcium channels. The latter is of particular interest given that Cav3 channels have a much lower conductance than HVA calcium channels and exhibit rapid inactivation that will substantially reduce the time for internal calcium accumulation.

The ability to coimmunoprecipitate Cav3 channels and either $\mathrm{KCa} 3.1$ or $\mathrm{Kv} 4$ channels is consistent with the physical requirements expected for a nanodomain interaction. In both cases the calcium-induced change in potassium channel function is prevented by internal perfusion of BAPTA but not EGTA. Moreover, the voltage-dependent and kinetic properties of Cav3-mediated calcium influx are transferred to KCa3.1 channels to produce a LVA transient outward current [34]. The potential conveyance of Cav3 voltage-dependent properties on $\mathrm{Kv} 4$ channels is less readily discerned given the similarities between these two channels in this parameter. However, the ability for calcium to modify the voltageinactivation profile of $\mathrm{Kv} 4$ channels signifies the ability for the complex to convert a voltage-gated $\mathrm{Kv} 4$ channel to one that is dependent on calcium influx. In fact, without Cav3 
calcium influx, the leftward shift in $\mathrm{Kv} 4 V_{\mathrm{h}}$ would substantially increase $\mathrm{Kv} 4$ inactivation at resting membrane potentials. Together, these data support the conclusion that Cav3 channels are positioned sufficiently close to $\mathrm{KCa} 3.1$ or $\mathrm{Kv} 4$ channels, and the sensitivity of calmodulin and KChIP3 as calcium sensors is sufficiently high to support a nanodomain interaction even with the relatively low conductance of Cav3 channels (Fig. 5a, b). Interestingly, the Cav3-Kv4 complex proves to be so highly sensitive to Cav3 calcium conductance that even subtle reductions in extracellular calcium during physiologically relevant input signals reduce $I_{\mathrm{A}}$ availability [6]. However, this sensitivity is valuable in allowing the complex to act as a novel sensor for extracellular calcium to modify stellate cell output in an adaptive manner.

In the case of $\mathrm{KCa} 1.1$ channels, the situation is less clear. On the one hand, coimmunoprecipitation data indicate that Cav3 and KCa1.1 channels are part of a macromolecular signaling complex that places KCa1.1 channels close to the source of Cav3 calcium entry. But Cav3-mediated activation of KCa1.1 is less reliable in being blocked by as little as $5 \mathrm{mM}$ internal EGTA in both tsA-201 and MVN cells. Activating $\mathrm{KCa} 1.1$ in tsA-201 cells further required an initial prepulse command to $-30 \mathrm{mV}$ to maximally activate Cav3 current. Once sufficient activation of KCa1.1 was achieved, Cav3 calcium influx left-shifted the voltage dependence of
KCa1.1 activation, with additional evidence for voltagedependent inactivation of $\mathrm{KCa} 1.1$, as expected for steadystate inactivation properties of Cav3 channels. These data are perplexing in presenting a calcium-dependent activation process more reminiscent of a microdomain interaction. However, this implies a distance between the channels of 50-200 nm, which is greater than what one expects from a direct molecular interaction. In contrast, it has been shown that physical signaling complexes between N-type calcium channels and KCa1.1 channels allow a functional interaction at the level of a nanodomain (Fig. 5c). The key difference from Cav3 channels is a much larger open probability and single channel conductance of N-type channels, such that each channel is sufficient to provide the calcium levels needed for KCa1.1 activation [134].

Lessons learned from studying calmodulin regulation of calcium-dependent inactivation (CDI) of HVA channels can be used to explain this apparent discrepancy. For both L-type and $\mathrm{P} / \mathrm{Q}$-type channels, calmodulin is preassociated with the calcium channel. A rise in intracellular calcium results in calcium binding to calmodulin, thereby triggering a rearrangement of the channel-calmodulin complex to cause CDI [35]. Calmodulin has two high-affinity and two low-affinity binding sites for calcium. CDI of L-type channels is dependent on the high-affinity calcium binding lobes, whereas that of $\mathrm{P} / \mathrm{Q}-$

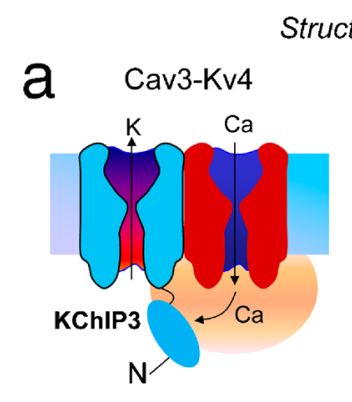

Structural and functional nanodomains
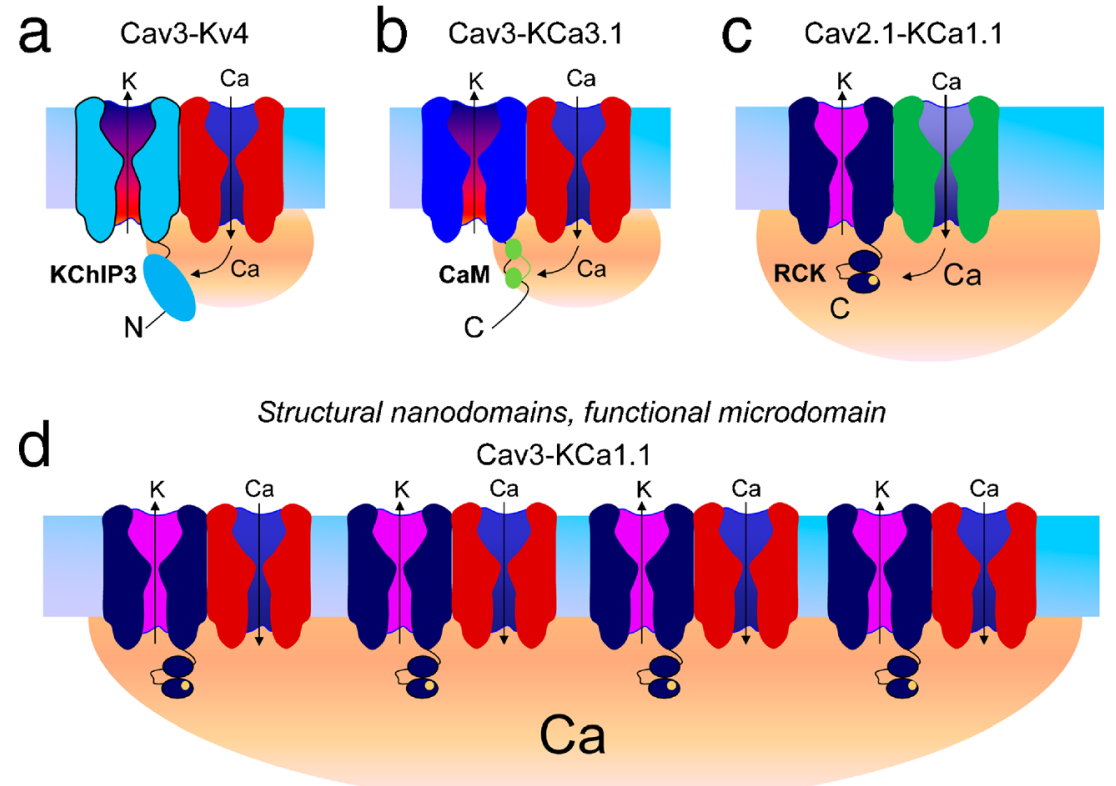

Fig. 5 Interactions between calcium channels and potassium channels. Shaded regions (orange) represent the size of calcium domains. a Cav3 channels physically associate with Kv4 channels, placing the Kv4 channel and its associated KChiIP3 accessory protein within a calcium nanodomain formed by calcium entering through the pore of an individual Cav3 channel. b Similarly, $\mathrm{KCa} 3.1$ channels associated with a Cav3 channel are placed within this nanodomain, and the high calcium affinity of calmodulin ensures that KCa3.1 channels can be gated by an individual Cav3 channel. $\mathbf{c}$ KCa1.1 channels require a higher calcium concentration for activation. In the case of N-type channels, the higher open probability and greater single channel conductance than Cav3 channels is sufficient to activate an associated $\mathrm{KCa} 1.1$ channel. d In contrast, individual Cav3 channels do not provide sufficient calcium to activate $\mathrm{KCa} 1.1$ channels, instead requiring the concerted action of multiple Cav3-KCa1.1 complexes to raise calcium to sufficiently high levels to permit KCa1.1 activation, accounting for the EGTA sensitivity of this process despite the physical association of the channels 
type channels relies on the low-affinity binding sites. Therefore, calcium entry via an individual L-type channel is sufficient to raise calcium concentrations near the high-affinity sites on calmodulin to trigger CDI, making this resistant to internal EGTA [70]. The situation is different with P/Q-type channels, where the lower affinity of calmodulin for calcium requires a much larger rise in intracellular calcium for CDI to occur. Importantly, this rise in calcium cannot be supported by an individual channel but rather requires the concerted action of many channels [70]. Thus, despite the fact that each channel is already associated with a calmodulin molecule, CDI of P/Qtype channels is EGTA sensitive.

We hypothesize that apparent incongruencies in data showing a Cav3-KCa1.1 macromolecular complex that functions at the level of a microdomain parallel what is observed with CDI of P/Q-type channels. Much like the low-affinity calcium binding site on calmodulin, the calcium binding site on $\mathrm{KCa} 1.1$ channels has a low affinity for calcium. Therefore, calcium entry through a single Cav3 calcium channel is insufficient to activate $\mathrm{KCa} 1.1$ even though the two proteins are in close proximity. However, a concerted entry of calcium through multiple Cav3-KCa1.1 complexes is proposed to support a global rise in calcium that is sufficiently high to activate KCa1.1 and, thus like CDI of P/Q-type channels, is sensitive to internal EGTA (Fig. 5d). An additional consideration concerns the stoichiometry between Cav3 calcium and an associated potassium channel. Potassium channels are tetrameric assemblies, and thus, in principle, each potassium channel could interact with four Cav3 channels, although experimental evidence for a 4:1 stoichiometry is lacking. Along these lines, each potassium channel may have four different calcium sensors (i.e., four KChiP proteins, four calmodulin molecules, or four RCK domains/calcium bowls). Hence, the calcium dynamics of potassium channel activation/modulation may be immensely complex, giving rise to unexpected EGTA sensitivities that would complicate distance estimates based on the use of intracellular calcium buffers alone.

\section{Concluding remarks}

As we have discussed here, Cav3 channels can form molecular associations with three different potassium channel classes that rely on very different mechanisms for calcium sensing. The primary determinants for functional coupling at either a microdomain or nanodomain level appear to be defined by the relative conductance of the calcium channel and sensitivity of the calcium sensor to changes in intracellular calcium concentration. As result, initial work on the Cav3-KCa1.1 complex revealed a new form of calcium-dependent activation of potassium channels not originally expected according to the conventional means of defining interactions at the micro- and nanodomain levels (i.e., the use of buffer sensitivity alone is insufficient to paint a complete picture). Another novel aspect is the observation that $\mathrm{KCa} 3.1$ channels are in fact expressed in CNS neurons where they regulate neuronal output, in part by forming a Cav3-KCa3.1 channel complex that can activate in the subthreshold region. The ability for Cav3 calcium current to activate $\mathrm{KCa} 3.1$ channels further confers voltage-dependent gating properties from Cav3 channels onto a normally voltage-insensitive $\mathrm{KCa} 3.1$ channel. Conversely, Cav3 channels confer calcium sensitivity onto the normally purely voltage-sensitive Kv4 channels via KChIP3 proteins. This altogether widens the traditional view of different ion channels acting independently - instead, there is intricate interplay between different ionic channels through formation of macromolecular signaling complexes. What remains to be examined is whether there is feedback regulation that allows the associated potassium channels to regulate Cav3 channels. Furthermore, it remains to be determined if the formation of signaling complexes can affect other channel features, such as trafficking to the plasma membrane and specific localization within neurons. Our observations that Cav3-K channel complexes can profoundly impact neuronal output may thus be only one of many important aspects of these molecular associations.

Acknowledgments We gratefully acknowledge the contributions of numerous laboratory members in the experimental and analytical components of the work summarized here. This work was supported by operating grants from the Canadian Institute of Health Research. R.W.T. and G.W.Z. are AIHS Scientists and G.W.Z. holds a Canada Research Chair.

Open AccessThis article is distributed under the terms of the Creative Commons Attribution License which permits any use, distribution, and reproduction in any medium, provided the original author(s) and the source are credited.

\section{References}

1. Adelman JP, Maylie J, Sah P (2012) Small-conductance Ca2+activated K+ channels: form and function. Annu Rev Physiol 74: 245-269. doi:10.1146/annurev-physiol-020911-153336

2. Alvina K, Khodakhah K (2008) Selective regulation of spontaneous activity of neurons of the deep cerebellar nuclei by N-type calcium channels in juvenile rats. J Physiol 586:2523-2538. doi:10.1113/ jphysiol.2007.148197

3. An WF et al (2000) Modulation of A-type potassium channels by a family of calcium sensors. Nature 403:553-556

4. Anderson D et al (2010) Regulation of neuronal activity by Cav3Kv4 channel signaling complexes. Nat Neurosci 13:333-337. doi: $10.1038 / \mathrm{nn} .2493$

5. Anderson D, Rehak R, Hameed S, Mehaffey WH, Zamponi GW, Turner RW (2010) Regulation of the K(V)4.2 complex by Ca(V)3.1 calcium channels. Channels (Austin) 4(3):163-167

6. Anderson D et al (2013) The Cav3-Kv4 complex acts as a calcium sensor to maintain inhibitory charge transfer during extracellular calcium fluctuations. J Neurosci 33:7811-7824. doi:10.1523/ JNEUROSCI.5384-12.2013

7. Autret L, Mechaly I, Scamps F, Valmier J, Lory P, Desmadryl G (2005) The involvement of Cav3.2/alpha1H T-type calcium 
channels in excitability of mouse embryonic primary vestibular neurones. J Physiol 567:67-78. doi:10.1113/jphysiol.2005.089342

8. Basalingappa KM, Rajendran VM, Wonderlin WF (2011) Characteristics of Kcnn4 channels in the apical membranes of an intestinal epithelial cell line. Am J Physiol Gastrointest Liver Physiol 301:G905-G911. doi:10.1152/ajpgi.00558.2010

9. Begenisich $\mathrm{T}$ et al (2004) Physiological roles of the intermediate conductance, Ca2+-activated potassium channel Kcnn4. J Biol Chem 279:47681-47687. doi:10.1074/jbc.M409627200

10. Berkefeld $\mathrm{H}$ et al (2006) BKCa-Cav channel complexes mediate rapid and localized $\mathrm{Ca} 2+$-activated $\mathrm{K}+$ signaling. Science 314:615620. doi:10.1126/science.1132915

11. Berkefeld H, Fakler B (2008) Repolarizing responses of BKCa-Cav complexes are distinctly shaped by their Cav subunits. J Neurosci 28:8238-8245. doi:10.1523/JNEUROSCI.2274-08.2008

12. Berkefeld H, Fakler B, Schulte U (2010) Ca2+-activated K+ channels: from protein complexes to function. Physiol Rev 90:14371459. doi:10.1152/physrev.00049.2009

13. Bouhy D et al (2011) Inhibition of the $\mathrm{Ca}(2)(+)$-dependent $\mathrm{K}(+)$ channel, KCNN4/KCa3.1, improves tissue protection and locomotor recovery after spinal cord injury. J Neurosci 31:16298-16308. doi:10.1523/JNEUROSCI.0047-11.2011

14. Bourque CW (1988) Transient calcium-dependent potassium current in magnocellular neurosecretory cells of the rat supraoptic nucleus. J Physiol 397:331-347

15. Burgoyne RD, Haynes LP (2012) Understanding the physiological roles of the neuronal calcium sensor proteins. Mol Brain 5:2. doi:10. 1186/1756-6606-5-2

16. Cain SM, Snutch TP (2013) T-type calcium channels in burst-firing, network synchrony, and epilepsy. Biochim Biophys Acta 1828: 1572-1578. doi:10.1016/j.bbamem.2012.07.028

17. Catterall WA, Perez-Reyes E, Snutch TP, Striessnig J (2005) International Union of Pharmacology. XLVIII. Nomenclature and structure-function relationships of voltage-gated calcium channels. Pharmacol Rev 57:411-425. doi:10.1124/pr.57.4.5

18. Chen QX, Wong RK (1991) Intracellular Ca2+ suppressed a transient potassium current in hippocampal neurons. J Neurosci 11: 337-343

19. Chen YJ, Raman G, Bodendiek S, O'Donnell ME, Wulff H (2011) The KCa3.1 blocker TRAM-34 reduces infarction and neurological deficit in a rat model of ischemia/reperfusion stroke. J Cereb Blood Flow Metab 31:2363-2374. doi:10.1038/jcbfm.2011.101

20. Cheong E, Shin HS (2013) T-type Ca2+ channels in normal and abnormal brain functions. Physiol Rev 93:961-992. doi:10.1152/ physrev.00010.2012

21. Chevalier M, Lory P, Mironneau C, Macrez N, Quignard JF (2006) Ttype $\mathrm{CaV} 3.3$ calcium channels produce spontaneous low-threshold action potentials and intracellular calcium oscillations. Eur J Neurosci 23:2321-2329. doi:10.1111/j.1460-9568.2006.04761.x

22. Clark BD et al (2008) DPP6 localization in brain supports function as a Kv4 channel associated protein. Front Mol Neurosci 1:8. doi: 10.3389/neuro.02.008.2008

23. Coetzee WA et al (1999) Molecular diversity of K+ channels. Ann N Y Acad Sci 868:233-285

24. Covarrubias $M$ et al (2008) The neuronal Kv4 channel complex. Neurochem Res 33:1558-1567. doi:10.1007/s11064-008-9650-8

25. Crunelli V, Toth TI, Cope DW, Blethyn K, Hughes SW (2005) The 'window' T-type calcium current in brain dynamics of different behavioural states. J Physiol 562:121-129. doi:10.1113/jphysiol. 2004.076273

26. Cueni L et al (2008) T-type Ca2+ channels, SK2 channels and SERCAs gate sleep-related oscillations in thalamic dendrites. Nat Neurosci 11:683-692. doi:10.1038/nn.2124

27. Cueni L, Canepari M, Adelman JP, Luthi A (2009) Ca(2+) signaling by T-type $\mathrm{Ca}(2+)$ channels in neurons. Pflugers Arch 457:11611172. doi:10.1007/s00424-008-0582-6
28. Cui J, Yang H, Lee US (2009) Molecular mechanisms of BK channel activation. Cell Mol Life Sci 66:852-875. doi:10.1007/ s00018-008-8609-x

29. Deleuze C et al (2012) T-type calcium channels consolidate tonic action potential output of thalamic neurons to neocortex. J Neurosci 32:12228-12236. doi:10.1523/JNEUROSCI.1362-12.2012

30. Dougherty K, Tu L, Deutsch C, Covarrubias M (2009) The dipeptidyl-aminopeptidase-like protein 6 is an integral voltage sensor-interacting beta-subunit of neuronal K(V) 4.2 channels. Channels (Austin) 3:122-128

31. Dreyfus FM et al (2010) Selective T-type calcium channel block in thalamic neurons reveals channel redundancy and physiological impact of I(T)window. J Neurosci 30:99-109. doi:10.1523/ JNEUROSCI.4305-09.2010

32. Edgerton JR, Reinhart PH (2003) Distinct contributions of small and large conductance $\mathrm{Ca} 2+$-activated $\mathrm{K}+$ channels to rat Purkinje neuron function. J Physiol 548:53-69

33. Engbers JD, Anderson D, Tadayonnejad R, Mehaffey WH, Molineux ML, Turner RW (2011) Distinct roles for I(T) and I(H) in controlling the frequency and timing of rebound spike responses. J Physiol 589:5391-5413. doi:10.1113/jphysiol.2011.215632

34. Engbers JD et al (2012) Intermediate conductance calciumactivated potassium channels modulate summation of parallel fiber input in cerebellar Purkinje cells. Proc Natl Acad Sci U S A 109: 2601-2606. doi:10.1073/pnas.1115024109

35. Erickson MG, Alseikhan BA, Peterson BZ, Yue DT (2001) Preassociation of calmodulin with voltage-gated $\mathrm{Ca}(2+)$ channels revealed by FRET in single living cells. Neuron 31:973-985

36. Fakler B, Adelman JP (2008) Control of K(Ca) channels by calcium nano/microdomains. Neuron 59:873-881. doi:10.1016/j.neuron. 2008.09.001

37. Fanger CM et al (1999) Calmodulin mediates calcium-dependent activation of the intermediate conductance $\mathrm{KCa}$ channel, IKCa1. J Biol Chem 274:5746-5754

38. Foeger NC, Norris AJ, Wren LM, Nerbonne JM (2012) Augmentation of Kv4.2-encoded currents by accessory dipeptidyl peptidases 6 and 10 subunits reflects selective cell surface Kv4.2 protein stabilization. J Biol Chem 287(12):9640-9650. doi:10. 1074/jbc.M111.324574

39. Furness JB et al (2003) Expression of intermediate conductance potassium channel immunoreactivity in neurons and epithelial cells of the rat gastrointestinal tract. Cell Tissue Res 314:179-189. doi: 10.1007/s00441-003-0808-z

40. Furness JB et al (2004) Intermediate conductance potassium (IK) channels occur in human enteric neurons. Auton Neurosci 112:9397. doi:10.1016/j.autneu.2004.02.003

41. Gardos G (1958) The function of calcium in the potassium permeability of human erythrocytes. Biochim Biophys Acta 30:653-654

42. Ghanshani S et al (2000) Upregulation of the IKCa1 potassium channel during T-cell activation. Molecular mechanism and functional consequences. J Biol Chem 275:37137-37149. doi:10.1074/ jbc.M003941200

43. Gittis AH, du Lac S (2007) Firing properties of GABAergic versus non-GABAergic vestibular nucleus neurons conferred by a differential balance of potassium currents. J Neurophysiol 97:3986-3996. doi:10.1152/jn.00141.2007

44. Gittis AH, Moghadam SH, du Lac S (2010) Mechanisms of sustained high firing rates in two classes of vestibular nucleus neurons: differential contributions of resurgent $\mathrm{Na}, \mathrm{Kv} 3$, and BK currents. J Neurophysiol 104:1625-1634. doi:10.1152/jn.00378.2010

45. Grunnet M, Kaufmann WA (2004) Coassembly of big conductance $\mathrm{Ca} 2+$-activated $\mathrm{K}+$ channels and L-type voltage-gated $\mathrm{Ca} 2+$ channels in rat brain. J Biol Chem 279:36445-36453. doi:10.1074/jbc. M402254200

46. Gu N, Vervaeke K, Storm JF (2007) BK potassium channels facilitate high-frequency firing and cause early spike frequency 
adaptation in rat CA1 hippocampal pyramidal cells. J Physiol 580: 859-882. doi:10.1113/jphysiol.2006.126367

47. Gutman GA et al (2005) International Union of Pharmacology. LIII. Nomenclature and molecular relationships of voltage-gated potassium channels. Pharmacol Rev 57:473-508

48. Hannah RM, Dunn KM, Bonev AD, Nelson MT (2011) Endothelial $\mathrm{SK}(\mathrm{Ca})$ and $\mathrm{IK}(\mathrm{Ca})$ channels regulate brain parenchymal arteriolar diameter and cortical cerebral blood flow. J Cereb Blood Flow Metab 31:1175-1186. doi:10.1038/jcbfm.2010.214

49. Heinemann U, Lux HD, Gutnick MJ (1977) Extracellular free calcium and potassium during paroxysmal activity in the cerebral cortex of the cat. Exp Brain Res 27:237-243

50. Hirst GD, Johnson SM, van Helden DF (1985) The slow calciumdependent potassium current in a myenteric neurone of the guineapig ileum. J Physiol 361:315-337

51. Iftinca MC, Zamponi GW (2009) Regulation of neuronal T-type calcium channels. Trends Pharmacol Sci 30:32-40. doi:10.1016/j. tips.2008.10.004

52. Ishii TM, Silvia C, Hirschberg B, Bond CT, Adelman JP, Maylie J (1997) A human intermediate conductance calcium-activated potassium channel. Proc Natl Acad Sci U S A 94:11651-11656

53. Jensen BS, Strobaek D, Olesen SP, Christophersen P (2001) The $\mathrm{Ca} 2+$-activated $\mathrm{K}+$ channel of intermediate conductance: a molecular target for novel treatments? Curr Drug Targets 2:401-422

54. Jerng HH, Pfaffinger PJ, Covarrubias M (2004) Molecular physiology and modulation of somatodendritic A-type potassium channels. Mol Cell Neurosci 27:343-369

55. Jerng HH, Kunjilwar K, Pfaffinger PJ (2005) Multiprotein assembly of Kv4.2, KChIP3 and DPP10 produces ternary channel complexes with ISA-like properties. J Physiol 568:767-788

56. Jerng HH, Lauver AD, Pfaffinger PJ (2007) DPP10 splice variants are localized in distinct neuronal populations and act to differentially regulate the inactivation properties of Kv4-based ion channels. Mol Cell Neurosci 35:604-624. doi:10.1016/j.mcn.2007.03.008

57. Joiner WJ, Wang LY, Tang MD, Kaczmarek LK (1997) hSK4, a member of a novel subfamily of calcium-activated potassium channels. Proc Natl Acad Sci U S A 94:11013-11018

58. Joiner WJ, Khanna R, Schlichter LC, Kaczmarek LK (2001) Calmodulin regulates assembly and trafficking of SK4/IK1 Ca2+activated K+ channels. J Biol Chem 276:37980-37985. doi:10. 1074/jbc.M104965200

59. Kaulin YA, De Santiago-Castillo JA, Rocha CA, Nadal MS, Rudy B, Covarrubias M (2009) The dipeptidyl-peptidase-like protein DPP6 determines the unitary conductance of neuronal Kv4.2 channels. J Neurosci 29:3242-3251. doi:10.1523/JNEUROSCI.4767-08.2009

60. Kaushal V, Koeberle PD, Wang Y, Schlichter LC (2007) The Ca2+activated $\mathrm{K}+$ channel $\mathrm{KCNN} 4 / \mathrm{KCa} 3.1$ contributes to microglia activation and nitric oxide-dependent neurodegeneration. J Neurosci 27:234-244. doi:10.1523/JNEUROSCI.3593-06.2007

61. Khanna R, Chang MC, Joiner WJ, Kaczmarek LK, Schlichter LC (1999) hSK4/hIK1, a calmodulin-binding KCa channel in human T lymphocytes. Roles in proliferation and volume regulation. J Biol Chem 274:14838-14849

62. Kim LA, Furst J, Butler MH, Xu S, Grigorieff N, Goldstein SA (2004) Ito channels are octomeric complexes with four subunits of each Kv4.2 and $\mathrm{K}+$ channel-interacting protein 2. J Biol Chem 279:5549-5554

63. Kohler M et al (1996) Small-conductance, calcium-activated potassium channels from mammalian brain. Science 273:1709-1714

64. Lambert RC, Bessaih T, Leresche N (2006) Modulation of neuronal Ttype calcium channels. CNS Neurol Disord Drug Targets 5:611-627

65. Lambert RC, Bessaih T, Crunelli V, Leresche N (2013) The many faces of T-type calcium channels. Pflugers Arch. doi:10.1007/ s00424-013-1353-6, epub

66. Lancaster B, Adams PR (1986) Calcium-dependent current generating the afterhyperpolarization of hippocampal neurons. J Neurophysiol 55:1268-1282
67. Lancaster B, Nicoll RA (1987) Properties of two calcium-activated hyperpolarizations in rat hippocampal neurones. J Physiol 389:187203

68. Lancaster B, Zucker RS (1994) Photolytic manipulation of Ca2+ and the time course of slow, $\mathrm{Ca}(2+)$-activated $\mathrm{K}+$ current in rat hippocampal neurones. J Physiol 475:229-239

69. Lasser-Ross N, Ross WN, Yarom Y (1997) Activity-dependent $[\mathrm{Ca} 2+] \mathrm{i}$ changes in guinea pig vagal motoneurons: relationship to the slow afterhyperpolarization. J Neurophysiol 78:825-834

70. Liang H, DeMaria CD, Erickson MG, Mori MX, Alseikhan BA, Yue DT (2003) Unified mechanisms of Ca2+ regulation across the $\mathrm{Ca} 2+$ channel family. Neuron 39:951-960

71. Liu BS, Ferreira R, Lively S, Schlichter LC (2013) Microglial SK3 and SK4 currents and activation state are modulated by the neuroprotective drug, riluzole. J Neuroimmune Pharmacol 8:227-237. doi:10.1007/s11481-012-9365-0

72. Logsdon NJ, Kang J, Togo JA, Christian EP, Aiyar J (1997) A novel gene, hKCa4, encodes the calcium-activated potassium channel in human T lymphocytes. J Biol Chem 272:32723-32726

73. Lusin JD, Vanarotti M, Li C, Valiveti A, Ames JB (2008) NMR structure of DREAM: implications for $\mathrm{Ca}(2+)$-dependent DNA binding and protein dimerization. Biochemistry 47:2252-2264. doi:10.1021/bi7017267

74. MacDermott AB, Weight FF (1982) Action potential repolarization may involve a transient, $\mathrm{Ca} 2+$-sensitive outward current in a vertebrate neurone. Nature 300:185-188

75. Maffie J, Rudy B (2008) Weighing the evidence for a ternary protein complex mediating A-type $\mathrm{K}+$ currents in neurons. J Physiol 586: 5609-5623. doi:10.1113/jphysiol.2008.161620

76. Marrion NV, Tavalin SJ (1998) Selective activation of Ca2+-activated $\mathrm{K}+$ channels by co-localized $\mathrm{Ca} 2+$ channels in hippocampal neurons. Nature 395:900-905. doi:10.1038/27674

77. McKay BE et al (2006) Cav3 T-type calcium channel isoforms differentially distribute to somatic and dendritic compartments in rat central neurons. Eur J Neurosci 24:2581-2594. doi:10.1111/j. 1460-9568.2006.05136.x

78. Minor DL Jr, Findeisen F (2010) Progress in the structural understanding of voltage-gated calcium channel $(\mathrm{CaV})$ function and modulation. Channels (Austin) 4:459-474. doi:10.4161/chan.4.6. 12867

79. Mittmann W, Koch U, Hausser M (2005) Feed-forward inhibition shapes the spike output of cerebellar Purkinje cells. J Physiol 563: 369-378. doi:10.1113/jphysiol.2004.075028

80. Molineux ML, Fernandez FR, Mehaffey WH, Turner RW (2005) Atype and T-type currents interact to produce a novel spike latencyvoltage relationship in cerebellar stellate cells. J Neurosci 25: 10863-10873. doi:10.1523/JNEUROSCI.3436-05.2005

81. Molineux ML et al (2006) Specific T-type calcium channel isoforms are associated with distinct burst phenotypes in deep cerebellar nuclear neurons. Proc Natl Acad Sci U S A 103:5555-5560

82. Molineux ML, Mehaffey WH, Tadayonnejad R, Anderson D, Tennent AF, Turner RW (2008) Ionic factors governing rebound burst phenotype in rat deep cerebellar neurons. J Neurophysiol 100: 2684-2701. doi:10.1152/jn.90427.2008

83. Mongan LC et al (2005) The distribution of small and intermediate conductance calcium-activated potassium channels in the rat sensory nervous system. Neuroscience 131:161-175. doi:10.1016/j. neuroscience.2004.09.062

84. Monteil A, Chemin J, Bourinet E, Mennessier G, Lory P, Nargeot J (2000) Molecular and functional properties of the human alpha( $1 \mathrm{G})$ subunit that forms T-type calcium channels. J Biol Chem 275:6090 6100

85. Muller A, Kukley M, Uebachs M, Beck H, Dietrich D (2007) Nanodomains of single $\mathrm{Ca} 2+$ channels contribute to action potential repolarization in cortical neurons. J Neurosci 27:483-495. doi:10. 1523/JNEUROSCI.3816-06.2007 
86. Nadal MS, Amarillo Y, Vega-Saenz de Miera E, Rudy B (2001) Evidence for the presence of a novel Kv4-mediated A-type $\mathrm{K}(+)$ channel-modifying factor. J Physiol 537:801-809

87. Nadal MS, Amarillo Y, Vega-Saenz de Miera E, Rudy B (2006) Differential characterization of three alternative spliced isoforms of DPPX. Brain Res 1094:1-12. doi:10.1016/j.brainres.2006.03.106

88. Nadin BM, Pfaffinger PJ (2010) Dipeptidyl peptidase-like protein 6 is required for normal electrophysiological properties of cerebellar granule cells. J Neurosci 30:8551-8565. doi:10.1523/JNEUROSCI. 5489-09.2010

89. Nelson AB, Krispel CM, Sekirnjak C, du Lac S (2003) Long-lasting increases in intrinsic excitability triggered by inhibition. Neuron 40 : 609-620

90. Neylon CB et al (2004) Intermediate-conductance calcium-activated potassium channels in enteric neurones of the mouse: pharmacological, molecular and immunochemical evidence for their role in mediating the slow afterhyperpolarization. J Neurochem 90:1414-1422. doi:10.1111/j.1471-4159.2004.02593.x

91. Neylon CB, Fowler CJ, Furness JB (2006) Regulation of the slow afterhyperpolarization in enteric neurons by protein kinase A. Auton Neurosci 126-127:258-263. doi:10.1016/j.autneu.2006.02.028

92. Nguyen TV et al (2007) Effects of compounds that influence IK (KCNN4) channels on afterhyperpolarizing potentials, and determination of IK channel sequence, in guinea pig enteric neurons. J Neurophysiol 97:2024-2031. doi:10.1152/jn.00935.2006

93. Nicholson C, Bruggencate GT, Steinberg R, Stockle H (1977) Calcium modulation in brain extracellular microenvironment demonstrated with ion-selective micropipette. Proc Natl Acad Sci U S A $74: 1287-1290$

94. Norris AJ, Foeger NC, Nerbonne JM (2010) Interdependent roles for accessory KChIP2, KChIP3, and KChIP4 subunits in the generation of Kv4-encoded IA channels in cortical pyramidal neurons. J Neurosci 30:13644-13655. doi:10.1523/JNEUROSCI.2487-10. 2010

95. Osawa $\mathrm{M}$ et al (2001) Calcium-regulated DNA binding and oligomerization of the neuronal calcium-sensing protein, calsenilin/ DREAM/KChIP3. J Biol Chem 276:41005-41013. doi:10.1074/ jbc.M105842200

96. Pedarzani P, Stocker M (2008) Molecular and cellular basis of small- and intermediate-conductance, calcium-activated potassium channel function in the brain. Cell Mol Life Sci 65:3196-3217. doi: 10.1007/s00018-008-8216-x

97. Perez-Reyes E (2003) Molecular physiology of low-voltageactivated t-type calcium channels. Physiol Rev 83:117-161

98. Pioletti M, Findeisen F, Hura GL, Minor DL Jr (2006) Threedimensional structure of the KChIP1-Kv4.3 T1 complex reveals a cross-shaped octamer. Nat Struct Mol Biol 13:987-995

99. Pongs O, Schwarz JR (2010) Ancillary subunits associated with voltage-dependent K+ channels. Physiol Rev 90:755-796. doi:10. 1152/physrev.00020.2009

100. Powell KL, Cain SM, Snutch TP, O'Brien TJ (2013) Low threshold T-type calcium channels as targets for novel epilepsy treatments. $\mathrm{Br}$ J Clin Pharmacol. doi:10.1111/bcp.12205, epub

101. Rehak R, Bartoletti TM, Engbers JD, Berecki G, Turner RW, Zamponi GW (2013) Low voltage activation of KCa1.1 current by Cav3-KCa1.1 complexes. PLoS One 8:e61844

102. Rehak R, Bartoletti TM, Engbers JDT, Berecki G, Turner RW, Zamponi GW (2013) Low voltage activation of KCa1.1 current by Cav3-KCa1.1 complexes. PLoS One 8:e61844

103. Ren X, Hayashi Y, Yoshimura N, Takimoto K (2005) Transmembrane interaction mediates complex formation between peptidase homologues and Kv4 channels. Mol Cell Neurosci 29: 320-332

104. Rhodes KJ et al (2004) KChIPs and Kv4 alpha subunits as integral components of A-type potassium channels in mammalian brain. J Neurosci 24:7903-7915. doi:10.1523/JNEUROSCI.0776-04.2004
105. Sailer CA et al (2002) Regional differences in distribution and functional expression of small-conductance $\mathrm{Ca} 2+$-activated $\mathrm{K}+$ channels in rat brain. J Neurosci 22:9698-9707

106. Sailer CA, Kaufmann WA, Marksteiner J, Knaus HG (2004) Comparative immunohistochemical distribution of three smallconductance $\mathrm{Ca} 2+$-activated potassium channel subunits, SK1, SK2, and SK3 in mouse brain. Mol Cell Neurosci 26:458-469

107. Saviane C, Mohajerani MH, Cherubini E (2003) An ID-like current that is downregulated by $\mathrm{Ca} 2+$ modulates information coding at CA3-CA3 synapses in the rat hippocampus. J Physiol 552:513-524

108. Serodio P, Rudy B (1998) Differential expression of Kv4 K+ channel subunits mediating subthreshold transient $\mathrm{K}+$ (A-type) currents in rat brain. J Neurophysiol 79:1081-1091

109. Shao, L.R., Halvorsrud, R., Borg-Graham, L., Storm, J.F. (1999) The role of BK-type $\mathrm{Ca} 2+-$ dependent $\mathrm{K}+$ channels in spike broadening during repetitive firing in rat hippocampal pyramidal cells. $\mathrm{J}$ Physiol 521 Pt 1:135-146

110. Shibata R et al (2003) A fundamental role for KChIPs in determining the molecular properties and trafficking of Kv4.2 potassium channels. J Biol Chem 278:36445-36454

111. Smith MR, Nelson AB, Du Lac S (2002) Regulation of firing response gain by calcium-dependent mechanisms in vestibular nucleus neurons. J Neurophysiol 87:2031-2042. doi:10.1152/jn.00821.2001

112. Spafford JD, Dunn T, Smit AB, Syed NI, Zamponi GW (2006) In vitro characterization of L-type calcium channels and their contribution to firing behavior in invertebrate respiratory neurons. J Neurophysiol 95:42-52. doi:10.1152/jn.00658.2005

113. Stocker M, Pedarzani P (2000) Differential distribution of three $\mathrm{Ca}(2+)$-activated $\mathrm{K}(+)$ channel subunits, SK1, SK2, and SK3, in the adult rat central nervous system. Mol Cell Neurosci 15:476-493. doi:10.1006/mene.2000.0842

114. Stockle H, Ten Bruggencate G (1980) Fluctuation of extracellular potassium and calcium in the cerebellar cortex related to climbing fiber activity. Neuroscience 5:893-901

115. Storm JF (1987) Action potential repolarization and a fast afterhyperpolarization in rat hippocampal pyramidal cells. J Physiol 385: 733-759

116. Storm JF (1990) Potassium currents in hippocampal pyramidal cells. Prog Brain Res 83:161-187

117. Sun X, Gu XQ, Haddad GG (2003) Calcium influx via L- and Ntype calcium channels activates a transient large-conductance $\mathrm{Ca} 2+-$ activated $\mathrm{K}+$ current in mouse neocortical pyramidal neurons. $\mathrm{J}$ Neurosci 23:3639-3648

118. Swensen AM, Bean BP (2003) Ionic mechanisms of burst firing in dissociated Purkinje neurons. J Neurosci 23:9650-9663

119. Thompson-Vest N, Shimizu Y, Hunne B, Furness JB (2006) The distribution of intermediate-conductance, calcium-activated, potassium (IK) channels in epithelial cells. J Anat 208:219-229. doi:10. 1111/j.1469-7580.2006.00515.x

120. Todorovic SM, Jevtovic-Todorovic V (2011) T-type voltage-gated calcium channels as targets for the development of novel pain therapies. Br J Pharmacol 163:484-495

121. Tscherter A et al (2011) Minimal alterations in T-type calcium channel gating markedly modify physiological firing dynamics. J Physiol 589:1707-1724. doi:10.1113/jphysiol.2010.203836

122. Tsien RW, Lipscombe D, Madison D, Bley K, Fox A (1995) Reflections on $\mathrm{Ca}(2+)$-channel diversity, 1988-1994. Trends Neurosci 18:52-54

123. van Welie I, du Lac S (2011) Bidirectional control of BK channel open probability by CAMKII and PKC in medial vestibular nucleus neurons. J Neurophysiol 105:1651-1659. doi:10.1152/jn.00058. 2011

124. Vandorpe DH et al (1998) cDNA cloning and functional characterization of the mouse $\mathrm{Ca} 2+$-gated $\mathrm{K}+$ channel, mIK1. Roles in regulatory volume decrease and erythroid differentiation. J Biol Chem 273:21542-21553 
125. Viana F, Bayliss DA, Berger AJ (1993) Multiple potassium conductances and their role in action potential repolarization and repetitive firing behavior of neonatal rat hypoglossal motoneurons. J Neurophysiol 69:2150-2163

126. Vogalis F, Furness JB, Kunze WA (2001) Afterhyperpolarization current in myenteric neurons of the guinea pig duodenum. $\mathrm{J}$ Neurophysiol 85:1941-1951

127. Vogalis F, Harvey JR, Furness JB (2002) TEA- and apamin-resistant $\mathrm{K}(\mathrm{Ca})$ channels in guinea-pig myenteric neurons: slow AHP channels. J Physiol 538:421-433

128. Vogalis F, Harvey JR, Neylon CB, Furness JB (2002) Regulation of $\mathrm{K}+$ channels underlying the slow afterhyperpolarization in enteric afterhyperpolarization-generating myenteric neurons: role of calcium and phosphorylation. Clin Exp Pharmacol Physiol 29:935-943

129. Vogalis F, Storm JF, Lancaster B (2003) SK channels and the varieties of slow after-hyperpolarizations in neurons. Eur $\mathrm{J}$ Neurosci 18:3155-3166

130. Walker SD, Dora KA, Ings NT, Crane GJ, Garland CJ (2001) Activation of endothelial cell IK(Ca) with 1-ethyl-2benzimidazolinone evokes smooth muscle hyperpolarization in rat isolated mesenteric artery. Br J Pharmacol 134:1548-1554. doi:10. 1038/sj.bjp.0704415

131. Wang $\mathrm{H}$ et al (2007) Structural basis for modulation of Kv4 K+ channels by auxiliary KChIP subunits. Nat Neurosci 10:32-39. doi: 10.1038/nn1822

132. Wang J, Morishima S, Okada Y (2003) IK channels are involved in the regulatory volume decrease in human epithelial cells. Am J Physiol Cell Physiol 284:C77-C84. doi:10.1152/ajpcell.00132.2002

133. Weatherall KL, Goodchild SJ, Jane DE, Marrion NV (2010) Small conductance calcium-activated potassium channels: from structure to function. Prog Neurobiol 91:242-955. doi:10.1016/j.pneurobio. 2010.03.002
134. Weber AM, Wong FK, Tufford AR, Schlichter LC, Matveev V, Stanley EF (2010) N-type Ca2+ channels carry the largest current: implications for nanodomains and transmitter release. Nat Neurosci 13:1348-1350. doi:10.1038/nn.2657

135. Wei AD, Gutman GA, Aldrich R, Chandy KG, Grissmer S, Wulff H (2005) International Union of Pharmacology. LII. Nomenclature and molecular relationships of calcium-activated potassium channels. Pharmacol Rev 57:463-472. doi:10.1124/pr.57.4.9

136. Weiss $\mathrm{N}$ et al (2012) A Ca(v)3.2/syntaxin-1A signaling complex controls T-type channel activity and low-threshold exocytosis. J Biol Chem 287:2810-2818. doi:10.1074/jbc.M111.290882

137. Weiss N, Zamponi GW (2013) Control of low-threshold exocytosis by T-type calcium channels. Biochim Biophys Acta 1828:1579 1586. doi:10.1016/j.bbamem.2012.07.031

138. Wolfart J, Roeper J (2002) Selective coupling of T-type calcium channels to SK potassium channels prevents intrinsic bursting in dopaminergic midbrain neurons. J Neurosci 22:3404-3413

139. Womack MD, Chevez C, Khodakhah K (2004) Calcium-activated potassium channels are selectively coupled to $\mathrm{P} / \mathrm{Q}$-type calcium channels in cerebellar Purkinje neurons. J Neurosci 24:8818-8822

140. Wulff H, Castle NA (2010) Therapeutic potential of KCa3.1 blockers: recent advances and promising trends. Expert Rev Clin Pharmacol 3:385-396. doi:10.1586/ecp.10.11

141. Xia XM et al (1998) Mechanism of calcium gating in smallconductance calcium-activated potassium channels. Nature 395: 503-507. doi:10.1038/26758

142. Zamponi GW, Lory P, Perez-Reyes E (2010) Role of voltage-gated calcium channels in epilepsy. Pflugers Arch 460:395-403. doi:10. 1007/s00424-009-0772-x

143. Zbicz KL, Weight FF (1985) Transient voltage and calciumdependent outward currents in hippocampal CA3 pyramidal neurons. J Neurophysiol 53:1038-1058 